\title{
Type I interferons as stimulators of DC-mediated cross-priming: impact on anti-tumor response
}

\section{Giovanna Schiavoni *, Fabrizio Mattei and Lucia Gabriele}

Department of Hematology, Oncology and Molecular Medicine, Istituto Superiore di Sanità, Rome, Italy

\section{Edited by:}

Kristian Michael Hargadon,

Hampden-Sydney College, USA

\section{Reviewed by:}

Pedro Berraondo, Centro de

Investigación Médica Aplicada, Spain

Edith Janssen, Cincinnati Children's

Hospital Research Foundation, USA

\section{*Correspondence:}

Giovanna Schiavoni, Experimental Immunotherapy Unit, Department of Hematology, Oncology and Molecular Medicine, Istituto Superiore di Sanità, Viale Regina Elena, 299, Rome 00161, Italy

e-mail: giovanna.schiavoni@iss.it
Induction of potent tumor-specific cytotoxic T-cell responses is a fundamental objective in anticancer therapeutic strategies. This event requires that antigen-presenting cells present tumor-associated antigens ( $\mathrm{Ag})$ on their MHC class-I molecule, in a process termed crosspresentation. Dendritic cells (DC) are particularly keen on this task and can induce the cross-priming of $\mathrm{CD}^{+} \mathrm{T}$ cells, when exposed to danger or inflammatory signals that stimulate their activation. Type I interferons (IFN-I), a family of long-known immunostimulatory cytokines, have been proven to produce optimal activation signal for DC-induced cross-priming. Recent in vitro and in vivo evidences have suggested that IFN-I-stimulated cross-priming by DC against tumor-associated Ag is a key mechanism for cancer immunosurveillance and may be usefully exploited to boost anti-tumor $\mathrm{CD} 8^{+} \mathrm{T}$-cell responses. Here, we will review the cross-presentation properties of different DC subsets, with special focus on cell-associated and tumor Ag, and discuss how IFN-I can modify this function, with the aim of identifying more specific and effective strategies for improving anticancer responses.

Keywords: type I interferon, interferon alpha, cross-priming, dendritic cells, dendritic cell subsets, cancer, tumorassociated antigen, immunosurveillance

\section{INTRODUCTION}

Anti-tumor immune responses are evoked by several effector cells. These include both innate immune cells, like NK cells and macrophages, and cells of the adaptive immunity. Among these, $\mathrm{CD}^{+} \mathrm{T}$ cells are ideal tumoricidals, due to their capacity to recognize and kill malignant cells in an antigen (Ag)-specific fashion and to establish a long-lasting protection. The activation of anti-tumor $\mathrm{CD}^{+}{ }^{+}$-cell responses is fulfilled through a process known as cross-priming and requires the uptake of extracellular Ag also in the form of tumor cells by the antigen-presenting cell (APC), which subsequently delivers the engulfed material to a distinct endosomal/lysosomal pathway that allows the processed peptides to be presented on MHC class-I (MHC-I) molecules (cross-presentation) (1).

Among APC, dendritic cells (DC) have been described as the sole cell type able to cross-present cell-associated $\mathrm{Ag}$ and studies on both mouse and human models have revealed that distinct DC subsets display differential capacities to perform this process resulting in the induction of immunity or tolerance. In this respect, for cross-presentation to result in cross-priming, three signals must be delivered by DC: (i) loading and cross-presentation of cellderived Ag onto MHC-I, (ii) appropriate co-stimulation through membrane molecules, and (iii) secretion of pro-inflammatory cytokines. Among cytokines produced by DC and capable of triggering DC activation, type I interferons (IFN-I) have been shown to play a major role in promoting cross-priming against both soluble proteins and cell-associated Ag, such as Ag derived from tumor apoptotic cells.

Here we discuss the most recent advances in Ag crosspresentation properties by several types of DC and on the capacity of IFN-I to turn on $\mathrm{CD} 8^{+} \mathrm{T}$-cell cross-priming.

\section{SUBSETS CAPABLE OF MEDIATING CROSS-PRIMING MOUSE DC}

In the murine immune system several DC subtypes have been characterized (2). The spleen contains at least five subsets distinguished by expression of specific surface markers: plasmacytoid DC (pDC; CD11 $\left.\mathrm{c}^{\text {low }} \mathrm{PDCA}-1^{+} \mathrm{B} 220\right), \mathrm{CD} 8 \alpha \mathrm{DC}$ $\left(\mathrm{CD} 8 \alpha^{+} \mathrm{CD} 4^{-} \mathrm{CD} 11 \mathrm{~b}^{-}\right)$, CD11b DC $\left(\mathrm{CD} 8 \alpha^{-} \mathrm{CD} 4^{-} \mathrm{CD} 11 \mathrm{~b}^{+}\right)$, $\mathrm{CD} 4 \mathrm{DC}\left(\mathrm{CD} 8 \alpha^{-} \mathrm{CD} 4^{+} \mathrm{CD} 11 \mathrm{~b}^{+}\right)$, and merocytic DC (mcDC; $\left.\mathrm{CD} 8 \alpha^{-} \mathrm{CD} 4^{-} \mathrm{CD} 11 \mathrm{~b}^{-}\right)$. These DC subsets markedly differ in their abilities to capture and cross-present antigenic material and only some of them can cross-present cell-associated $\mathrm{Ag}(3)$.

$\mathrm{CD} 8 \alpha$ DC is the most efficient DC subset in Ag crosspresentation uniquely able to prime $\mathrm{CD} 8^{+} \mathrm{T}$ cells against cellassociated Ag in vivo (4-6). In the steady-state, CD $8 \alpha$ DC capture dead cells resulting from constitutive turnover and play a central role in self-tolerance $(6,7)$. The in vivo relevance of $\mathrm{CD} 8 \alpha$ $\mathrm{DC}$ in $\mathrm{CD}^{+}{ }^{+}$-cell cross-priming against cell-associated Ag has been better clarified by studies with mice devoid of this DC subset. Mice deficient for either transcription factors Batf3 or NFIL3/E4BP4, both lacking CD8 $\alpha$ DC selectively, display impaired cross-priming of $\mathrm{CD}^{+} \mathrm{T}$ cells against cell-associated $\mathrm{Ag}(8,9)$. Similarly, IRF- $8^{-1-}$ mice, which are devoid of CD $8 \alpha$ DC and pDC, display impaired capacity to cross-present both soluble and tumor cell-derived Ag $(10,11)$.

Initial studies showing that $\mathrm{CD} 8 \alpha \mathrm{DC}$ capture cellular Ag more efficiently than other DC subsets suggested that this was the principal mechanism for increased cross-presentation ability by CD $8 \alpha$ DC $(5,12)$. Indeed, CD8 $\alpha$ DC selectively express some receptors, such as CLEC9A or Tim-3, involved in the recognition of necrotic and apoptotic cells, respectively, and implicated in crosspresentation of cellular Ag (13-15). Additional studies unraveled 
that $\mathrm{CD} 8 \alpha \mathrm{DC}$ also possess a special processing machinery that delivers the internalized Ag onto the MHC-I processing pathway (16). Such machinery involves the activity of the small GTPase Rac2, selectively operating in CD8 $\alpha$ DC, and the subcellular assembly of the NADPH oxidase complex (NOX2) to phagosomes that maintains a high phagosomal $\mathrm{pH}$ and thus facilitates cross-presentation (17).

The lymph nodes (LN) contain additional DC subtypes, termed migratory DC, arising from non-lymphoid tissues where they normally reside. Of the two types of migratory DC described, namely $\mathrm{CD}_{103}{ }^{-} \mathrm{CD} 11 \mathrm{~b}^{+}$and $\mathrm{CD} 103^{+} \mathrm{CD} 11 \mathrm{~b}^{-}$, only the latter has been described to cross-present cellular Ag captured either in the lung (18) or in the skin (19). The shared efficiency for Ag crosspresentation by $\mathrm{CD} 8 \alpha \mathrm{DC}$ and $\mathrm{CD} 103^{+} \mathrm{DC}$ has been attributed to a developmental relationship, since these two DC subsets have a common dependence on the transcription factors Batf3, Flt3L, Id2, and IRF8 for their differentiation (20-22). Recent findings showed that $\mathrm{CD} 8 \alpha \mathrm{DC}$ and $\mathrm{CD} 103^{+}$DC specifically co-express $\mathrm{XCR} 1$, a receptor for $\mathrm{CD}^{+} \mathrm{T}$-cell-secreted XCL1 that couples DC cross-presentation to induction of $\mathrm{CD}^{+}$T-cell immunity (23, 24). XCR1 was found to be a conserved specific marker also for additional murine DC subtypes (including a small percentage of mcDC and of $\mathrm{CD}_{103^{-}}$DC) and for human DC subsets devoted to cross-presentation of cell-associated Ag (25-27).

Janssen's group reported that mcDC capture dying cells, although less efficiently than $\mathrm{CD} 8 \alpha \mathrm{DC}$, and cross-prime CD8 ${ }^{+}$ $\mathrm{T}$ cells for an extended time due to prolonged Ag storage (3, 28). In vivo, mcDC induce tumor-specific CTL responses in B16 melanoma-bearing mice (28). Of note, injection of tumor vaccineloaded mcDC, but not of CD8 $\alpha$ DC, elicited protective responses from subsequent tumor challenge in mice in a vaccination EL4 thymoma model and resulted in therapeutic eradication of established EL-4 and B16 melanoma tumors $(28,29)$.

Although cross-presentation of soluble proteins by mouse $\mathrm{pDC}$ can occur upon Toll-like receptor (TLR) engagement (30), there is no evidence that $\mathrm{pDC}$ may cross-present cell-associated Ag. Instead, pDC can indirectly enhance $\mathrm{CD} 8^{+} \mathrm{T}$-cell cross-priming, through production of IFN-I and other soluble mediators (3134). The capacity of CD11b DC to cross-present cellular Ag is also weak. In a murine model of mesothelioma expressing influenza virus hemagglutinin, as a membrane-bound neo-tumor $\mathrm{Ag}$, one group has reported that both $\mathrm{CD} 8 \alpha \mathrm{DC}$ and CD11b DC from tumor-draining LN could cross-present membrane hemagglutinin (35). This observation suggests that the anatomical location may affect the efficacy of CD11b DC for tumor Ag cross-presentation.

\section{HUMAN DC}

Human DC also display some heterogeneity. In the blood, DC may be essentially distinguished into $\mathrm{BDCA1}^{+}$myeloid $\mathrm{DC}(\mathrm{mDC})$, $\mathrm{BDCA}^{+} \mathrm{mDC}$, and $\mathrm{pDC}$. $\mathrm{BDCA}^{+} \mathrm{mDC}$ have been reported to cross-present Ag on their MHC-I molecules more efficiently than other DC populations. Due to functional and phylogenetic similarities, this subset is thought to be the human equivalent of mouse CD8 $\alpha$ DC (36-38). BDCA3 ${ }^{+}$mDCs selectively express CLEC9A and XCR1 and efficiently cross-present Ag derived from dead cells $(25,36,37)$.
The role of human $\mathrm{pDC}$ as professional APC in the crosspresentation of exogenous $\mathrm{Ag}$ is under intensive investigation. Tumor cells infected with a measles virus vaccine are able to induce tumor Ag cross-presentation by human $\mathrm{pDC}$ via production of large amounts of IFN- $\alpha$ (39). Furthermore, harnessing uptake receptors to deliver Ag to pDCs can enhance crosspresentation and IFN-I production, resulting in the generation of potent anti-tumor responses (40). The efficacy of pDC has been verified in a cohort of metastatic melanoma patients in whom activated pDC were found to induce Ag-specific T-cell responses and significantly extended overall survival (41). It has been recently shown that pDC cross-present soluble and cellassociated tumor Ag to cytotoxic $\mathrm{T}$ lymphocytes to the same degree as $\mathrm{BDCA}^{+} \operatorname{mDC}(42,43)$. Indeed, two recent reports argued on the notion that cross-presentation is restricted to certain human DC subsets. Amigorena's laboratory showed that freshly isolated tonsil-resident $\mathrm{pDC}, \mathrm{BDCA}^{+}$, and $\mathrm{BDCA}^{+}{ }^{+} \mathrm{mDC}$ cross-present soluble Ag with the same efficiency, displaying comparable phagosomal $\mathrm{pH}$, production of reactive oxygen species and capacity to export internalized proteins to the cytosol (44). Delamarre's group reported that the diverse human DC subsets are equally able to cross-present exogenous $\mathrm{Ag}$ to $\mathrm{CD} 8^{+} \mathrm{T}$ cells provided that the Ag is delivered to early endocytic compartments (43). These findings have extensive implications for vaccination strategies aiming at exploiting ex vivo-differentiated autologous DC, resembling primary DC subsets and endowed with strong cross-priming ability.

\section{ENHANCEMENT OF CROSS-PRESENTATION BY IFN-I IN MURINE DC}

In the steady-state or in the context of a tumor, DC crosspresentation of cell-associated $\mathrm{Ag}$ rarely results in $\mathrm{CD}^{+}{ }^{+} \mathrm{T}$-cell cross-priming due to lack of immunostimulatory signals capable of activating DC. IFN-I is the prototype inflammatory cytokine released upon infection or under physiological distress acting as a stimulus for DC cross-priming (45). In vivo, IFN-I induces CD8 ${ }^{+}$ T-cell cross-priming against viral or soluble protein Ag through DC stimulation (46). Recently, we showed that IFN-I can affect DC cross-presentation of cell-associated Ag. In vitro or in vivo exposure of CD $8 \alpha$ DC that have engulfed irradiated tumor cells to IFN-I resulted in three distinct effects: (i) increased retention of engulfed apoptotic material that correlated with decreased endosomal acidification and resulted in enhanced Ag cross-presentation, (ii) prolonged survival of phagocytic CD8 $\alpha$ DC, and (iii) phenotypic activation of the cross-presenting DC that resulted in DC "licensing" for cross-priming (10). Similar results were obtained using tumor cells killed by the chemotherapeutic agent cyclophosphamide as a source of antigenic material for CD8 $\alpha$ DC. In this setting, addition of IFN-I resulted in $\mathrm{CD}^{+}{ }^{+} \mathrm{T}$-cell cross-priming in vitro and tumor rejection in vivo (47).

Two different groups have recently reported the in vivo relevance of endogenous IFN-I signaling on CD8 $\alpha$ DC for promoting $\mathrm{CD}^{+}$T-cell-dependent spontaneous tumor rejection. Diamond et al. (48) showed that mice lacking IFN- $\alpha / \beta$ receptor 1 selectively in DC cannot reject methylcholanthrene-induced fibrosarcoma, a highly immunogenic tumor normally rejected by immunocompetent mice, and that $\mathrm{CD} 8 \alpha$ DC from these mice display 
defective Ag cross-presentation to $\mathrm{CD} 8^{+} \mathrm{T}$ cells. Similarly, by using IFN- $\alpha / \beta$ receptor $1^{-/-}$and Batf $3^{-/-}$mice transplanted with B16 melanoma, Fuertes et al. (49) reported that endogenous IFN-I, produced shortly after tumor challenge, was essential for intratumoral accumulation of CD $8 \alpha$ DC and for induction of tumor Ag-specific T-cell priming and tumor rejection via CD $8 \alpha$ DC stimulation. These studies underscore CD $8 \alpha$ DC as fundamental targets for endogenous IFN-I-mediated spontaneous immune control of a rising tumor.

Cross-priming mediated by $\mathrm{mcDC}$ also requires IFN-I. However, unlike CD $8 \alpha$ DC, which fail to produce IFN-I upon uptake of apoptotic cells, mcDC are able to do so. Adoptive transfer experiments revealed that this endogenous IFN-I acts in an autocrine manner to activate mcDC and is both necessary and sufficient for boosting $\mathrm{CD}^{+}{ }^{+} \mathrm{T}$-cell cross-priming against cell-associated $\mathrm{Ag}$ (28, 29). Of interest, endogenous IFN-I signaling in mcDC was essential for preserving internalized material from early degradation and endosomal acidification similarly to what observed with $\mathrm{CD} 8 \alpha$ DC exposed to exogenous IFN-I $(3,10)$. These findings suggest that IFN-I promote cross-priming in DC by exploiting a mechanism involving regulation of endosomal $\mathrm{pH}$ and $\mathrm{Ag}$ retention that direct the antigenic cargo toward the MHC-I processing pathway, as also observed with human DC (see below) (50). Thus, regulation of phagosomal acidification may be viewed as a strategy exploited by inflammatory signals, such as IFN-I, to switch on cross-priming in those DC subsets that under steady-state are devoted to tolerance induction and may provide a mechanism (coupled to MHC-I upregulation) by which IFN-I induce autoimmune reactions, namely by enhancing presentation of self Ag.

The ability of some compounds targeting TLR to stimulate $\mathrm{CD}^{+}$T-cell cross-priming has also been shown to occur through endogenous IFN-I production and subsequent DC stimulation $(51,52)$. The efficacy of CpG in cancer immunotherapy is dependent on cross-talk between pDC and conventional DC ( $\mathrm{mcDC}$ and CD8 $\alpha$ DC), the first serving as a source of IFN-I through TLR9 triggering and the latter responding to IFN-I to promote CD8 ${ }^{+} \mathrm{T}$ cell cross-priming and anti-tumor response in melanoma-bearing mice exposed to cryoablation (53).

\section{ENHANCEMENT OF CROSS-PRESENTATION BY IFN-I IN HUMAN DC}

Type I interferons exert multiple effects on human DC, affecting the major cellular pathways associated to their APC function, namely differentiation, maturation, and migration $(54,55)$. Human immature conventional DC treated in vitro with IFN-I upregulate the expression of MHC-I, CD40, CD80, CD86, and CD83 molecules resulting in a superior capacity to induce $\mathrm{CD} 8^{+} \mathrm{T}$-cell responses $(56,57)$. Moreover, IFN-I support the differentiation of human monocytes into DC with high capacity for Ag presentation (58). IFN $\alpha$ induces one-step differentiation of human monocytes into highly activated and partially mature DC (IFN $\alpha$-DC), retaining a marked phagocytic activity and exhibiting a special aptitude for inducing $\mathrm{CD}^{+} \mathrm{T}$-cell responses $(59,60)$. Studies on phenotype and functions of IFN $\alpha$-DC have pointed that these cells can resemble naturally occurring DC, generated from monocytes in response to danger signals, including infections when high levels of IFN-I are released (61-65). Indeed, subtypes of DC resembling IFN $\alpha$-DC have been observed in patients suffering from autoimmune or infectious diseases (54).

IFN $\alpha$-DC express markers involved in antigen processing such as CD208 and the scavenger receptor oxidized low-density lipoprotein receptor 1 (LOX-1), implicated in Ag uptake and CD8 ${ }^{+}$T-cell cross-priming (66). In vivo, IFN $\alpha$-DC generate cytotoxic responses and $\mathrm{CD} 8^{+} \mathrm{T}$-cell cross-priming against viral and tumor-associated Ag (59, 67-69). Efficient cross-presentation of tumor-associated Ag by IFN $\alpha$-DC loaded with apoptotic human melanoma cells was found to correlate with enhanced proteasome activity (68). In addition, studies employing soluble Ag point to an effect of IFN $\alpha$ in preserving $\mathrm{Ag}$ from early degradation, thus facilitating its routing onto MHC-I pathway (50). Thus, although the intracellular mechanisms underlying the superior efficiency of IFN $\alpha$-DC in Ag cross-presentation need to be clarified, these evidences suggest that IFN-I may control this process at diverse levels.

Interestingly, IFN $\alpha$-DC have been reported to exhibit some phenotypic features of $\mathrm{pDC}$ (70). We recently reported that IFN $\alpha$ DC and pDC share a similar miRNA signature as well as some phenotypic and molecular markers potentially accounting for common functional activities, such as IFN-I production upon viral infection. Moreover, IFN-I was also able to affect some functions of $\mathrm{pDC}$, including the expression of the $\mathrm{pDC}$-associated markers IRF-8 and TLR-9 (71).

\section{IMPORTANCE OF DC CROSS-PRIMING FOR ANTICANCER IMIMUNE RESPONSES AND PERSPECTIVES FOR EXPLOITATION OF IFN-I POTENTIATING EFFECT}

Several lines of evidence indicate that DC-mediated cross-priming is crucial for anti-tumor immunity (72). First, tumor-infiltrating DC purified from tumor samples have the capacity to cross-present tumor Ag in vitro (73). Second, priming in vivo of anti-tumor $\mathrm{T}$-cell responses can be abrogated in models in which DC subsets specialized for cross-presentation can be specifically depleted. Indeed, Batf $3^{-1-}$ mice are unable to reject highly immunogenic tumors due to defective cross-presentation by Batf $3^{-1-}$ DC, reduced tumor-infiltration of $\mathrm{CD}^{+} \mathrm{T}$ cells and failure to develop tumor-specific CTL (8).

The therapeutic anti-tumor potential of IFN-I has been appreciated since 1960s $(74,75)$. However, only recently it has become clearer how IFN-I participate in naturally occurring, protective immune responses to primary tumors, thus playing a prominent role in cancer immunosurveillance. In addition, IFN-I has been shown to be a crucial component of cancer-immunoediting, namely the process whereby the immune system suppresses cancer growth and shapes tumor immunogenicity $(76,77)$. These findings have renewed the interest in exploiting the anti-tumor potential of IFN-I in therapeutic and vaccination strategies against cancer.

Therapeutic approaches that involve either exogenous IFN-I administration or its induction within the tumor microenvironment have shown effects on $\mathrm{CD} 8^{+} \mathrm{T}$-cell responses via DC stimulation at various levels. In mice with established B16 tumors, radiotherapy induced a local increase in IFN-I expression by myeloid immune infiltrates that acted enhancing the cross-priming ability of tumor-infiltrating DC and was crucial for host therapeutic response (78). Furthermore, intratumoral delivery of IFN-I synergized with immunotherapy (79) and chemotherapy (47) to 


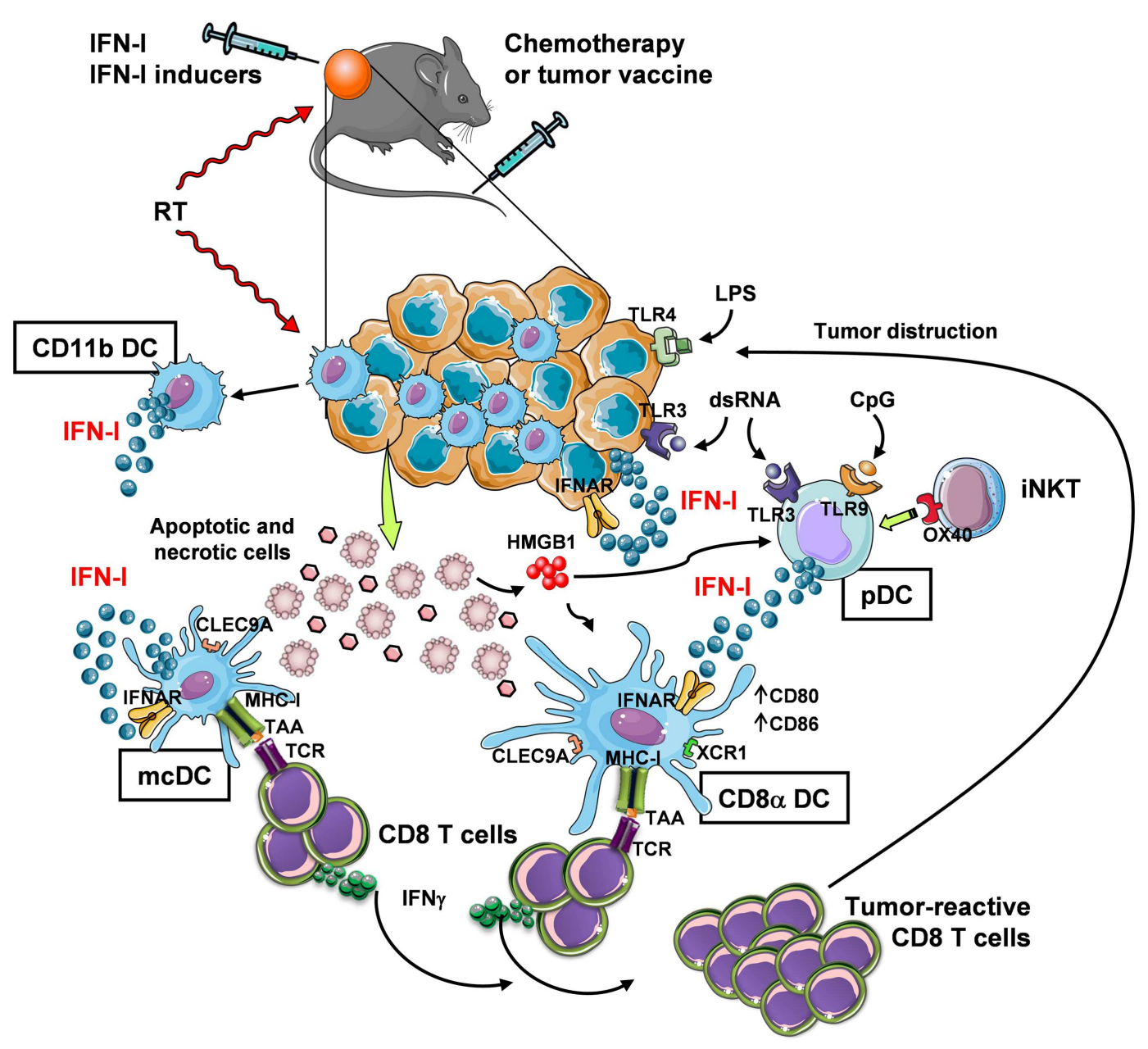

FIGURE 1 | In vivo induction of anti-tumor CD8 ${ }^{+}$T-cell responses through IFN-I-mediated DC cross-priming at the tumor site. Systemic

chemotherapy and local radiotherapy (RT) induce tumor cell death that result in the availability of antigenic material (which is otherwise provided by a tumor vaccine) for internalization by specialized $D C$ subsets, namely $m c D C$ and CD8 $\alpha$ DC. These subsets then cross-present the tumor-associated Ag (TAA) through their MHC-I complex to $\mathrm{CD} 8^{+} \mathrm{T}$ cells. In order to induce $\mathrm{CD} 8^{+} \mathrm{T}$-cell cross-priming, the cross-presenting DC need to be exposed to activation stimuli (DC licensing), such as IFN-I. While mcDC spontaneously produce IFN-I that act in an autocrine fashion to induce DC licensing for cross-priming, $\mathrm{CD} 8 \alpha \mathrm{DC}$ are unable to do so and require the exogenous cytokine. Thus, in the tumor site IFN-I may be made available in different manners: (1) via intratumoral injection, (2) by RT, which stimulates IFN-I release by infiltrating myeloid CD11b DC (and possibly other immune and non-immune cells), and (3) by intratumoral delivery of IFN-I-inducing substances, such as TLR ligands. Some TLR ligands can also bind to tumor cells that express TLR3 and TLR4 to trigger autocrine IFN-I production and stimulation of DC. Alternatively, TLR ligands, such as dsRNA and $\mathrm{CpG}$, stimulate $\mathrm{pDC}$ to produce large amounts of IFN-I. IFN-I secretion by pDC may also be stimulated by invariant NKT (iNKT) cells via OX40 and HMGB1 released by dying tumor cells. The final outcome of these events is the expansion of tumor-reactive CD8T cells with killing activity. induce therapeutic response in tumor-bearing mice that involved, in both cases, enhanced DC cross-presentation. Notably, IFN-I can enhance anti-tumor CTL responses also via direct effects on CD8 $\mathrm{T}$ cells, inducing their expansion and acquisition of effector functions thus improving therapeutic efficacy $(80,81)$.

With regard to protocols employing vaccine preparations, coadministration of $\mathrm{CpG}$ with a DC vaccine was found to overcome tumor-specific tolerance after stem cell transplantation, inducing protective anti-tumor response through CpG-induced IFN-I in vivo (82). Recently, Shimizu and colleagues showed that vaccination with B16 melanoma cells loaded with the invariant NKT cell ligand $\alpha$ GalCer stimulated tumor-reactive $\mathrm{CD} 8^{+}$memory $\mathrm{T}$ cells in a novel mechanism involving cross-talk between XCR1expressing DC and $\mathrm{pDC}$ via NKT-stimulated IFN- $\alpha$ production by pDC (33). Human studies also point to the use of IFN-I-inducers as promising approach to boost anti-tumor effector responses. The efficacy of topical application of the TLR7/8 agonist imiquimod, the only TLR agonist approved by FDA for skin cancer treatment, has been linked to local increase of IFN-I production, recruitment of DC and induction of tumor-reactive CTL (83). Finally, it is worth mentioning that tumor-derived IFN-I may also positively contribute to anti-tumor immune response. In virtue of their TLR expression, B16 melanoma cells were found to respond to ligands to TLR3 and TLR4 by releasing substantial levels of IFN-I that 
induced DC activation and resulted in tumor growth inhibition by the host $(84,85)$.

\section{CONCLUDING REMARKS}

Despite IFN- $\alpha$ has received approval for therapy of several neoplastic diseases, side effects of systemic long-term treatments and insufficiently high efficacy have challenged its use in current clinical protocols. Therefore, novel strategies to exploit IFN-I in therapeutic and vaccination protocols are needed that take into account, for example, controlled timing of administration to avoid negative feedback mechanisms in the responding immune cells $(58,86)$, and the involvement of active cross-talk between multiple types of immune cells that play different, non-overlapping roles within the tumor site. In this view, the combined use of chemotherapy or radiotherapy that kill cancer cells, providing source of Ag for DC, with exogenous IFN-I or compounds capable of inducing IFN-I in situ may be viewed as promising strategies for boosting DC cross-presentation and CTL induction within the tumor microenvironment (Figure 1).

\section{ACKNOWLEDGMENTS}

This study was funded by the Italian Association for Cancer research (AIRC) project no. 11610 to Lucia Gabriele.

\section{REFERENCES}

1. Joffre OP, Segura E, Savina A, Amigorena S. Cross-presentation by dendritic cells. Nat Rev Immunol (2012) 12:557-69. doi:10.1038/nri3254

2. Kushwah R, Hu J. Complexity of dendritic cell subsets and their function in the host immune system. Immunology (2011) 133:409-19. doi:10.1111/j.13652567.2011.03457.x

3. Thacker RI, Janssen EM. Cross-presentation of cell-associated antigens by mouse splenic dendritic cell populations. Front Immunol (2012) 3:41. doi:10.3389/ fimmu.2012.00041

4. den Haan JM, Lehar SM, Bevan MJ. CD8(+) but not CD8(-) dendritic cells cross-prime cytotoxic T cells in vivo. J Exp Med (2000) 192:1685-96. doi:10.1084/jem.192.12.1685

5. Iyoda T, Shimoyama S, Liu K, Omatsu Y, Akiyama Y, Maeda Y, et al. The CD8+ dendritic cell subset selectively endocytoses dying cells in culture and in vivo. J Exp Med (2002) 195:1289-302. doi:10.1084/jem.20020161

6. Shortman K, Heath WR. The CD8+ dendritic cell subset. Immunol Rev (2010) 234:18-31. doi:10.1111/j.0105-2896.2009.00870.x

7. Belz GT, Behrens GM, Smith CM, Miller JF, Jones C, Lejon K, et al. The CD8alpha(+) dendritic cell is responsible for inducing peripheral self-tolerance to tissue-associated antigens. J Exp Med (2002) 196:1099-104. doi:10.1084/jem. 20020861

8. Hildner K, Edelson BT, Purtha WE, Diamond M, Matsushita H, Kohyama M, et al. Batf3 deficiency reveals a critical role for CD8alpha+ dendritic cells in cytotoxic T cell immunity. Science (2008) 322:1097-100. doi:10.1126/science. 1164206

9. Kashiwada M, Pham NL, Pewe LL, Harty JT, Rothman PB. NFIL3/E4BP4 is a key transcription factor for CD8alpha(+) dendritic cell development. Blood (2011) 117:6193-7. doi:10.1182/blood-2010-07-295873

10. Lorenzi S, Mattei F, Sistigu A, Bracci L, Spadaro F, Sanchez M, et al. Type I IFNs control antigen retention and survival of CD8\{alpha $\}+$ dendritic cells after uptake of tumor apoptotic cells leading to cross-priming. J Immunol (2011) 186:5142-50. doi:10.4049/jimmunol.1004163

11. Schiavoni G, Mattei F, Sestili P, Borghi P, Venditti M, Morse HC III, et al. ICSBP is essential for the development of mouse type I interferon-producing cells and for the generation and activation of CD8alpha(+) dendritic cells. J Exp Med (2002) 196:1415-25. doi:10.1084/jem.20021263

12. Schulz O, Reis e Sousa C. Cross-presentation of cell-associated antigens by CD8alpha+ dendritic cells is attributable to their ability to internalize dead cells. Immunology (2002) 107:183-9. doi:10.1046/j.1365-2567.2002.01513.x
13. Nakayama M, Akiba H, Takeda K, Kojima Y, Hashiguchi M, Azuma M, et al. Tim-3 mediates phagocytosis of apoptotic cells and cross-presentation. Blood (2009) 113:3821-30. doi:10.1182/blood-2008-10-185884

14. Sancho D, Joffre OP, Keller AM, Rogers NC, Martinez D, Hernanz-Falcon P, et al. Identification of a dendritic cell receptor that couples sensing of necrosis to immunity. Nature (2009) 458:899-903. doi:10.1038/nature07750

15. Sancho D, Mourao-Sa D, Joffre OP, Schulz O, Rogers NC, Pennington DJ, et al. Tumor therapy in mice via antigen targeting to a novel, DC-restricted C-type lectin. J Clin Invest (2008) 118:2098-110. doi:10.1172/JCI34584

16. Schnorrer P, Behrens GM, Wilson NS, Pooley JL, Smith CM, El-Sukkari D, et al. The dominant role of CD8+ dendritic cells in cross-presentation is not dictated by antigen capture. Proc Natl Acad Sci U S A (2006) 103:10729-34. doi:10.1073/pnas.0601956103

17. Savina A, Peres A, Cebrian I, Carmo N, Moita C, Hacohen N, et al. The small GTPase Rac2 controls phagosomal alkalinization and antigen crosspresentation selectively in CD8(+) dendritic cells. Immunity (2009) 30:544-55. doi:10.1016/j.immuni.2009.01.013

18. del Rio ML, Rodriguez-Barbosa JI, Kremmer E, Forster R. CD103- and CD103+ bronchial lymph node dendritic cells are specialized in presenting and crosspresenting innocuous antigen to CD4+ and CD8+ T cells. J Immunol (2007) 178:6861-6.

19. Bedoui S, Whitney PG, Waithman J, Eidsmo L, Wakim L, Caminschi I, et al. Cross-presentation of viral and self antigens by skin-derived CD103+ dendritic cells. Nat Immunol (2009) 10:488-95. doi:10.1038/ni.1724

20. Edelson BT, Kc W, Juang R, Kohyama M, Benoit LA, Klekotka PA, et al. Peripheral CD103+ dendritic cells form a unified subset developmentally related to CD8alpha+ conventional dendritic cells. J Exp Med (2010) 207:823-36. doi:10.1084/jem.20091627

21. Ginhoux F, Liu K, Helft J, Bogunovic M, Greter M, Hashimoto D, et al. The origin and development of nonlymphoid tissue CD103+ DCs. J Exp Med (2009) 206:3115-30. doi:10.1084/jem.20091756

22. Hashimoto D, Miller J, Merad M. Dendritic cell and macrophage heterogeneity in vivo. Immunity (2011) 35:323-35. doi:10.1016/j.immuni.2011.09.007

23. Crozat K, Tamoutounour S, Vu Manh TP, Fossum E, Luche H, Ardouin L, et al. Cutting edge: expression of XCR1 defines mouse lymphoid-tissue resident and migratory dendritic cells of the CD8alpha+ type. J Immunol (2011) 187:4411-5. doi:10.4049/jimmunol.1101717

24. Dorner BG, Dorner MB, Zhou X, Opitz C, Mora A, Guttler S, et al. Selective expression of the chemokine receptor XCR1 on cross-presenting dendritic cells determines cooperation with CD8+ T cells. Immunity (2009) 31:823-33. doi:10.1016/j.immuni.2009.08.027

25. Bachem A, Guttler S, Hartung E, Ebstein F, Schaefer M, Tannert A, et al. Superior antigen cross-presentation and XCR1 expression define human CD11c+CD141+ cells as homologues of mouse CD8+ dendritic cells. J Exp Med (2010) 207:1273-81. doi:10.1084/jem.20100348

26. Bachem A, Hartung E, Guttler S, Mora A, Zhou X, Hegemann A, et al. Expression of XCR1 characterizes the Batf3-dependent lineage of dendritic cells capable of antigen cross-presentation. Front Immunol (2012) 3:214. doi:10.3389/fimmu. 2012.00214

27. Crozat K, Guiton R, Contreras V, Feuillet V, Dutertre CA, Ventre E, et al. The XC chemokine receptor 1 is a conserved selective marker of mammalian cells homologous to mouse CD8alpha+ dendritic cells. J Exp Med (2010) 207:1283-92. doi:10.1084/jem.20100223

28. Reboulet RA, Hennies CM, Garcia Z, Nierkens S, Janssen EM. Prolonged antigen storage endows merocytic dendritic cells with enhanced capacity to prime anti-tumor responses in tumor-bearing mice. J Immunol (2010) 185:3337-47. doi:10.4049/jimmunol.1001619

29. Hennies CM, Reboulet RA, Garcia Z, Nierkens S, Wolkers MC, Janssen EM. Selective expansion of merocytic dendritic cells and CD8DCs confers anti-tumour effect of Fms-like tyrosine kinase 3-ligand treatment in vivo. Clin Exp Immunol (2011) 163:381-91. doi:10.1111/j.1365-2249.2010.04305.x

30. Mouries J, Moron G, Schlecht G, Escriou N, Dadaglio G, Leclerc C. Plasmacytoid dendritic cells efficiently cross-prime naive $\mathrm{T}$ cells in vivo after TLR activation. Blood (2008) 112:3713-22. doi:10.1182/blood-2008-03-146290

31. Ali OA, Emerich D, Dranoff G, Mooney DJ. In situ regulation of DC subsets and T cells mediates tumor regression in mice. Sci Transl Med (2009) 1:8ra19. doi:10.1126/scitranslmed.3000359 
32. Liu C, Lou Y, Lizee G, Qin H, Liu S, Rabinovich B, et al. Plasmacytoid dendritic cells induce NK cell-dependent, tumor antigen-specific $\mathrm{T}$ cell crosspriming and tumor regression in mice. J Clin Invest (2008) 118:1165-75. doi:10.1172/JCI33583

33. Shimizu K, Asakura M, Shinga J, Sato Y, Kitahara S, Hoshino K, et al. Invariant NKT cells induce plasmacytoid dendritic cell (DC) cross-talk with conventional DCs for efficient memory CD8+ T cell induction. J Immunol (2013) 190:5609-19. doi:10.4049/jimmunol.1300033

34. Wei J, Waithman J, Lata R, Mifsud NA, Cebon J, Kay T, et al. Influenza A infection enhances cross-priming of CD8 $+\mathrm{T}$ cells to cell-associated antigens in a TLR7- and type I IFN-dependent fashion. J Immunol (2010) 185:6013-22. doi:10.4049/jimmunol.1002129

35. McDonnell AM, Prosser AC, van Bruggen I, Robinson BW, Currie AJ. CD8alpha+ DC are not the sole subset cross-presenting cell-associated tumor antigens from a solid tumor. Eur J Immunol (2010) 40:1617-27. doi:10.1002/eji. 200940153

36. Jongbloed SL, Kassianos AJ, McDonald KJ, Clark GJ, Ju X, Angel CE, et al. Human CD141+ (BDCA-3)+ dendritic cells (DCs) represent a unique myeloid DC subset that cross-presents necrotic cell antigens. J Exp Med (2010) 207:1247-60. doi:10.1084/jem.20092140

37. Poulin LF, Salio M, Griessinger E, Anjos-Afonso F, Craciun L, Chen JL, et al. Characterization of human DNGR-1+ BDCA3+ leukocytes as putative equivalents of mouse CD8alpha+ dendritic cells. J Exp Med (2010) 207:1261-71. doi:10.1084/jem.20092618

38. Crozat K, Guiton R, Guilliams M, Henri S, Baranek T, Schwartz-Cornil I, et al. Comparative genomics as a tool to reveal functional equivalences between human and mouse dendritic cell subsets. Immunol Rev (2010) 234:177-98. doi:10.1111/j.0105-2896.2009.00868.x

39. Guillerme JB, Boisgerault N, Roulois D, Menager J, Combredet C, Tangy F, et al. Measles virus vaccine-infected tumor cells induce tumor antigen crosspresentation by human plasmacytoid dendritic cells. Clin Cancer Res (2013) 19:1147-58. doi:10.1158/1078-0432.CCR-12-2733

40. Tel J, Sittig SP, Blom RA, Cruz LJ, Schreibelt G, Figdor CG, et al. Targeting uptake receptors on human plasmacytoid dendritic cells triggers antigen crosspresentation and robust type I IFN secretion. J Immunol (2013) 191:5005-12. doi:10.4049/jimmunol.1300787

41. Tel J, Aarntzen EH, Baba T, Schreibelt G, Schulte BM, Benitez-Ribas D, et al. Natural human plasmacytoid dendritic cells induce antigen-specific T-cell responses in melanoma patients. Cancer Res (2013) 73:1063-75. doi:10.1158/0008-5472. CAN-12-2583

42. Tel J, Schreibelt G, Sittig SP, Mathan TS, Buschow SI, Cruz LJ, et al. Human plasmacytoid dendritic cells efficiently cross-present exogenous Ags to CD8+ T cells despite lower Ag uptake than myeloid dendritic cell subsets. Blood (2013) 121:459-67. doi:10.1182/blood-2012-06-435644

43. Cohn L, Chatterjee B, Esselborn F, Smed-Sorensen A, Nakamura N, Chalouni $\mathrm{C}$, et al. Antigen delivery to early endosomes eliminates the superiority of human blood BDCA3+ dendritic cells at cross presentation. J Exp Med (2013) 210:1049-63. doi:10.1084/jem.20121251

44. Segura E, Durand M, Amigorena S. Similar antigen cross-presentation capacity and phagocytic functions in all freshly isolated human lymphoid organ-resident dendritic cells. J Exp Med (2013) 210:1035-47. doi:10.1084/jem.20121103

45. Le Bon A, Tough DF. Type I interferon as a stimulus for cross-priming. Cytokine Growth Factor Rev (2008) 19:33-40. doi:10.1016/j.cytogfr.2007.10.007

46. Le Bon A, Etchart N, Rossmann C, Ashton M, Hou S, Gewert D, et al. Crosspriming of CD8+ T cells stimulated by virus-induced type I interferon. Nat Immunol (2003) 4:1009-15. doi:10.1038/ni978

47. Schiavoni G, Sistigu A, Valentini M, Mattei F, Sestili P, Spadaro F, et al. Cyclophosphamide synergizes with type I interferons through systemic dendritic cell reactivation and induction of immunogenic tumor apoptosis. Cancer Res (2011) 71:768-78. doi:10.1158/0008-5472.CAN-10-2788

48. Diamond MS, Kinder M, Matsushita H, Mashayekhi M, Dunn GP, Archambault JM, et al. Type I interferon is selectively required by dendritic cells for immune rejection of tumors. J Exp Med (2011) 208:1989-2003. doi:10.1084/ jem.20101158

49. Fuertes MB, Kacha AK, Kline J, Woo SR, Kranz DM, Murphy KM, et al. Host type I IFN signals are required for antitumor CD8+ T cell responses through CD8\{alpha\}+ dendritic cells. J Exp Med (2011) 208:2005-16. doi:10.1084/jem. 20101159
50. Spadaro F, Lapenta C, Donati S, Abalsamo L, Barnaba V, Belardelli F, et al. IFN-alpha enhances cross-presentation in human dendritic cells by modulating antigen survival, endocytic routing, and processing. Blood (2012) 119:1407-17. doi:10.1182/blood-2011-06-363564

51. Gray RC, Kuchtey J, Harding CV. CpG-B ODNs potently induce low levels of IFN-alphabeta and induce IFN-alphabeta-dependent MHC-I crosspresentation in DCs as effectively as CpG-A and CpG-C ODNs. J Leukoc Biol (2007) 81:1075-85. doi:10.1189/jlb.1006606

52. Oh JZ, Kurche JS, Burchill MA, Kedl RM. TLR7 enables cross-presentation by multiple dendritic cell subsets through a type I IFN-dependent pathway. Blood (2011) 118:3028-38. doi:10.1182/blood-2011-04-348839

53. Nierkens S, den Brok MH, Garcia Z, Togher S, Wagenaars J, Wassink M, et al. Immune adjuvant efficacy of $\mathrm{CpG}$ oligonucleotide in cancer treatment is founded specifically upon TLR9 function in plasmacytoid dendritic cells. Cancer Res (2011) 71:6428-37. doi:10.1158/0008-5472.CAN-11-2154

54. Farkas A, Kemeny L. Interferon-alpha in the generation of monocyte-derived dendritic cells: recent advances and implications for dermatology. Br J Dermatol (2011) 165:247-54. doi:10.1111/j.1365-2133.2011.10301.x

55. Hansen M, Met O, Svane IM, Andersen MH. Cellular based cancer vaccines: type 1 polarization of dendritic cells. Curr Med Chem (2012) 19:4239-46. doi:10.2174/092986712802884213

56. Gallucci S, Lolkema M, Matzinger P. Natural adjuvants: endogenous activators of dendritic cells. Nat Med (1999) 5:1249-55. doi:10.1038/15200

57. Ito T, Amakawa R, Inaba M, Ikehara S, Inaba K, Fukuhara S. Differential regulation of human blood dendritic cell subsets by IFNs. I Immunol (2001) 166:2961-9.

58. Hervas-Stubbs S, Perez-Gracia JL, Rouzaut A, Sanmamed MF, Le Bon A, Melero I. Direct effects of type I interferons on cells of the immune system. Clin Cancer Res (2011) 17:2619-27. doi:10.1158/1078-0432.CCR-10-1114

59. Gabriele L, Borghi P, Rozera C, Sestili P, Andreotti M, Guarini A, et al. IFN-alpha promotes the rapid differentiation of monocytes from patients with chronic myeloid leukemia into activated dendritic cells tuned to undergo full maturation after LPS treatment. Blood (2004) 103:980-7. doi:10.1182/blood-2003-03-0981

60. Santini SM, Di Pucchio T, Lapenta C, Parlato S, Logozzi M, Belardelli F. The natural alliance between type I interferon and dendritic cells and its role in linking innate and adaptive immunity. J Interferon Cytokine Res (2002) 22:1071-80. doi:10.1089/10799900260442494

61. Belardelli F, Ferrantini M. Cytokines as a link between innate and adaptive antitumor immunity. Trends Immunol (2002) 23:201-8. doi:10.1016/S14714906(02)02195-6

62. Gigante M, Mandic M, Wesa AK, Cavalcanti E, Dambrosio M, Mancini V, et al. Interferon-alpha (IFN-alpha)-conditioned DC preferentially stimulate type-1 and limit Treg-type in vitro T-cell responses from RCC patients. J Immunother (2008) 31:254-62. doi:10.1097/CJI.0b013e318167b023

63. Santodonato L, D’Agostino G, Nisini R, Mariotti S, Monque DM, Spada M, et al. Monocyte-derived dendritic cells generated after a short-term culture with IFN-alpha and granulocyte-macrophage colony-stimulating factor stimulate a potent Epstein-Barr virus-specific CD8+ T cell response. J Immunol (2003) 170:5195-202.

64. Tosi D, Valenti R, Cova A, Sovena G, Huber V, Pilla L, et al. Role of crosstalk between IFN-alpha-induced monocyte-derived dendritic cells and NK cells in priming CD8+ T cell responses against human tumor antigens. J Immunol (2004) 172:5363-70.

65. Tough DF. Type I interferon as a link between innate and adaptive immunity through dendritic cell stimulation. Leuk Lymphoma (2004) 45:257-64. doi:10.1080/1042819031000149368

66. Parlato S, Romagnoli G, Spadaro F, Canini I, Sirabella P, Borghi P, et al. LOX-1 as a natural IFN-alpha-mediated signal for apoptotic cell uptake and antigen presentation in dendritic cells. Blood (2010) 115:1554-63. doi:10.1182/blood2009-07-234468

67. Lapenta C, Santini SM, Spada M, Donati S, Urbani F, Accapezzato D, et al. IFN-alpha-conditioned dendritic cells are highly efficient in inducing crosspriming CD8(+) T cells against exogenous viral antigens. Eur J Immunol (2006) 36:2046-60. doi:10.1002/eji.200535579

68. Lattanzi L, Rozera C, Marescotti D, D’Agostino G, Santodonato L, Cellini S, et al. IFN-alpha boosts epitope cross-presentation by dendritic cells via modulation of proteasome activity. Immunobiology (2010) 216:537-47. doi:10.1016/j.imbio. 2010.10 .003 
69. Santini SM, Lapenta C, Logozzi M, Parlato S, Spada M, Di Pucchio T, et al. Type I interferon as a powerful adjuvant for monocyte-derived dendritic cell development and activity in vitro and in Hu-PBL-SCID mice. J Exp Med (2000) 191:1777-88. doi:10.1084/jem.191.10.1777

70. Farkas A, Kemeny L. Monocyte-derived interferon-alpha primed dendritic cells in the pathogenesis of psoriasis: new pieces in the puzzle. Int Immunopharmacol (2012) 13:215-8. doi:10.1016/j.intimp.2012.04.003

71. Parlato S, Bruni R, Fragapane P, Salerno D, Marcantonio C, Borghi P, et al. IFN-alpha regulates Blimp-1 expression via miR-23a and miR-125b in both monocytes-derived DC and pDC. PLoS One (2013) 8:e72833. doi:10.1371/ journal.pone.0072833

72. Andersen BM, Ohlfest JR. Increasing the efficacy of tumor cell vaccines by enhancing cross priming. Cancer Lett (2012) 325:155-64. doi:10.1016/j.canlet. 2012.07.012

73. McDonnell AM, Robinson BW, Currie AJ. Tumor antigen cross-presentation and the dendritic cell: where it all begins? Clin Dev Immunol (2010) 2010:539519. doi:10.1155/2010/539519

74. Gresser I, Bourali C, Levy JP, Fontaine-Brouty-Boye D, Thomas MT. Increased survival in mice inoculated with tumor cells and treated with interferon preparations. Proc Natl Acad Sci U S A (1969) 63:51-7. doi:10.1073/pnas. 63.1 .51

75. Gresser I, Maury C, Brouty-Boye D. Mechanism of the antitumour effect of interferon in mice. Nature (1972) 239:167-8. doi:10.1038/239167a0

76. Dunn GP, Bruce AT, Sheehan KC, Shankaran V, Uppaluri R, Bui JD, et al. A critical function for type I interferons in cancer immunoediting. Nat Immunol (2005) 6:722-9. doi:10.1038/ni1213

77. Dunn GP, Koebel CM, Schreiber RD. Interferons, immunity and cancer immunoediting. Nat Rev Immunol (2006) 6:836-48. doi:10.1038/nri1961

78. Burnette BC, Liang H, Lee Y, Chlewicki L, Khodarev NN, Weichselbaum RR, et al. The efficacy of radiotherapy relies upon induction of type i interferondependent innate and adaptive immunity. Cancer Res (2011) 71:2488-96. doi:10.1158/0008-5472.CAN-10-2820

79. Dubrot J, Palazon A, Alfaro C, Azpilikueta A, Ochoa MC, Rouzaut A, et al. Intratumoral injection of interferon-alpha and systemic delivery of agonist anti-CD137 monoclonal antibodies synergize for immunotherapy. Int J Cancer (2011) 128:105-18. doi:10.1002/ijc.25333

80. Hervas-Stubbs S, Mancheno U, Riezu-Boj JI, Larraga A, Ochoa MC, Alignani D, et al. CD8 T cell priming in the presence of IFN-alpha renders CTLs with improved responsiveness to homeostatic cytokines and recall antigens: important traits for adoptive T cell therapy. J Immunol (2012) 189:3299-310. doi:10.4049/jimmunol.1102495

81. Hervas-Stubbs S, Riezu-Boj JI, Gonzalez I, Mancheno U, Dubrot J, Azpilicueta A, et al. Effects of IFN-alpha as a signal-3 cytokine on human naive and antigen-experienced CD8(+) T cells. Eur J Immunol (2010) 40:3389-402. doi:10.1002/eji.201040664

82. Horkheimer I, Quigley M, Zhu J, Huang X, Chao NJ, Yang Y. Induction of type I IFN is required for overcoming tumor-specific T-cell tolerance after stem cell transplantation. Blood (2009) 113:5330-9. doi:10.1182/blood-2008-05-155150

83. Pradere JP, Dapito DH, Schwabe RF. The Yin and Yang of Toll-like receptors in cancer. Oncogene (2013). doi:10.1038/onc.2013.302

84. Gatti G, Nunez NG, Nocera DA, Dejager L, Libert C, Giraudo C, et al. Direct effect of dsRNA mimetics on cancer cells induces endogenous IFN-beta production capable of improving dendritic cell function. Eur J Immunol (2013) 43:1849-61. doi:10.1002/eji.201242902

85. Nunez NG, Andreani V, Crespo MI, Nocera DA, Breser ML, Moron G, et al. IFNbeta produced by TLR4-activated tumor cells is involved in improving the antitumoral immune response. Cancer Res (2012) 72:592-603. doi:10.1158/00085472.CAN-11-0534

86. Odorizzi PM, Wherry EJ. Immunology. An interferon paradox. Science (2013) 340:155-6. doi:10.1126/science. 1237568

Conflict of Interest Statement: The authors declare that the research was conducted in the absence of any commercial or financial relationships that could be construed as a potential conflict of interest.

Received: 12 November 2013; accepted: 09 December 2013; published online: 25 December 2013.

Citation: Schiavoni G, Mattei F and Gabriele L (2013) Type I interferons as stimulators of DC-mediated cross-priming: impact on anti-tumor response. Front. Immunol. 4:483. doi: 10.3389/fimmu.2013.00483

This article was submitted to Tumor Immunity, a section of the journal Frontiers in Immunology.

Copyright (c) 2013 Schiavoni, Mattei and Gabriele. This is an open-access article distributed under the terms of the Creative Commons Attribution License (CC BY). The use, distribution or reproduction in other forums is permitted, provided the original author(s) or licensor are credited and that the original publication in this journal is cited, in accordance with accepted academic practice. No use, distribution or reproduction is permitted which does not comply with these terms. 